\title{
Carcinoma ex pleomorphic adenoma in a minor salivary gland: report of a case
}

\author{
Peter A. Reichart • Steffen Kalz • Annette Rabel • \\ Michael M. Bornstein
}

Published online: 9 October 2009

(C) Springer-Verlag 2009

\begin{abstract}
Background Carcinoma ex pleomorphic adenoma is exceedingly rare in minor salivary glands of the oral cavity. We present a case of carcinoma ex pleomorphic adenoma (CEPA) of the buccal mucosa in a 47 -year-old Turkish patient. The buccal mass was of a size of $1.5 \mathrm{~cm}$ located in the left cheek. Pleomorphic adenoma was the tentative diagnosis.

Methods The tumor was removed under local anesthesia. Histopathologic evaluation revealed a preexisting pleomorphic adenoma associated with adenoid tumor component with tubulo-cystic and papillary or pseudopapillary structures; CEPA was diagnosed. Capsular integrity was incomplete with infiltration by islands of metaplastic/ dysplastic epithelium.

Results Secondary surgery of the site was performed. No tumor tissue could be detected in the resection specimen. The patient is free of recurrence since 9 months.
\end{abstract}

Keywords Minor salivary gland tumor .

Pleomorphic adenoma - Carcinoma ex pleomorphic adenoma

P. A. Reichart $\cdot$ M. M. Bornstein $(\square)$

Department of Oral Surgery and Stomatology,

School of Dental Medicine, University of Bern,

Freiburgstrasse 7,

3010 Bern, Switzerland

e-mail: michael.bornstein@zmk.unibe.ch

S. Kalz $\cdot$ A. Rabel

Private Practice for Oral Surgery,

Berlin, Germany

\section{Introduction}

Carcinoma ex pleomorphic adenoma (CEPA) is defined as a pleomorphic adenoma from which an epithelial malignancy is derived [1]. CEPAs comprise about $3.6 \%$ of all salivary tumors and $12 \%$ of all salivary malignancies. Most CEPAs arise in the parotid gland. The proportion of benign versus malignant components can be variable.

CEPAs are subclassified into non-invasive, minimally invasive (about $1.5 \mathrm{~mm}$ penetration of the malignant component into extra capsular tissue), and invasive (more than $1.5 \mathrm{~mm}$ penetration into extra capsular tissue) [1] Recommended therapy is wide local excision, however, improved prognosis for minimally invasive tumors has been confirmed [2].

We present a case of CEPA with minimal invasion of the capsule in a buccal minor salivary gland of a 47-year-old male patient.

\section{Case presentation}

A 47-year-old Turkish male patient was referred by his medical practitioner for diagnosis and treatment of "a lump in the left cheek". The patient was a non-smoker. General health status was unremarkable. The patient had realized that there was a mass in his left cheek, but could not state for how long it had been present. Because his wife urged him to seek medical advice, he went to see his general medical practitioner.

Extraoral inspection did not reveal any pathology of the left cheek. Palpation of submandibular and cervical lymphnodes was negative. Clinically, the buccal oral mucosa of the left side was of normal color and texture. There were no signs of inflammation. The salivary papilla 
of the parotid gland was of normal size. The left parotid gland produced saliva of normal quality and quantity. Palpation of the left cheek revealed a swelling located in the area corresponding to the first mandibular premolar and to the first molar. The mass was of a size of about $1.5 \mathrm{~cm}$, and of an oval to round shape. It was firm, painless, and not fixed to the underlying soft tissues of the cheek.

After local anesthesia a horizontal incision of $2 \mathrm{~cm}$ allowed for exposure of the tumor mass. The lesion was encapsulated, and could easily be removed in toto by blunt preparation. The wound was closed using non-resorbable sutures. Wound healing was uneventful. The surgical specimen was of a size of $1.8 \times 1.3 \mathrm{~cm}$ (Fig. 1). Macroscopically, the tumor appeared to be encapsulated. When cut open (Fig. 2), a solid tumor mass of a yellowish-pinkish color was obvious. The specimen was immersed in formalin (4\%), and sent to the pathology laboratory with the tentative diagnosis of pleomorphic adenoma.

Histopathologically, a salivary gland tumor was diagnosed with residual normal salivary mucous gland tissue adjacent to the tumor (Fig. 3). The tumor was composed of pre-existing areas of pleomorphic adenoma characterized by a typical tubular-glandular component in a myxoid stroma (Fig. 4). A transitional zone showed myoepithelial and epithelial cells, and in close association adenoid tumor tissue with tubulocystic and papillary or pseudopapillary structures (Fig. 5). Cellular details revealed moderate nuclear pleomorphism, loss of chromatin, prominent nucleoli, and moderate mitotic activity. Capsular integrity was incomplete, and infiltration by islands of metaplastic epithelial cells of the capsule was observed (Figs. 6 and 7). Lymphangio-invasion could not clearly be demonstrated. With the presence of atypia and infiltration of the capsule, the diagnosis of carcinoma ex pleomorphic adenoma, minimal invasive variant, was made.

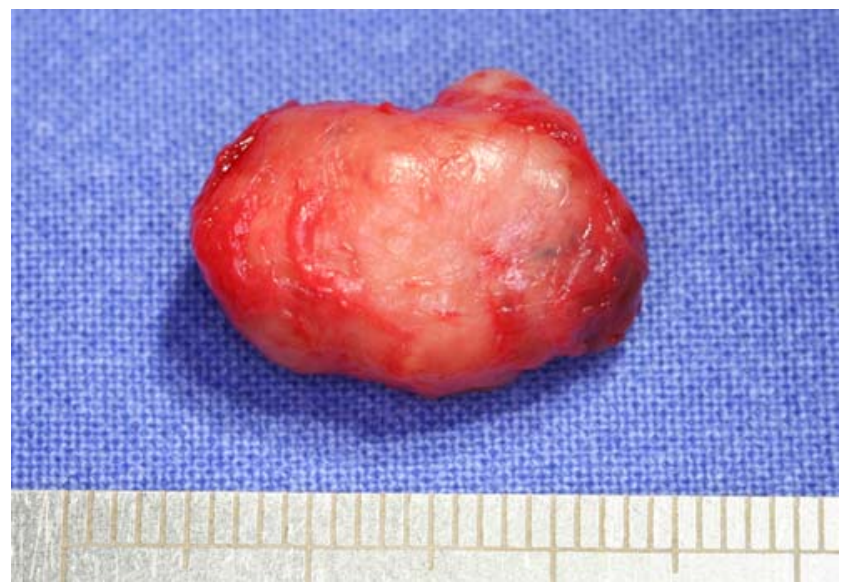

Fig. 1 Surgical specimen of the buccal tumor. Macroscopically, the capsule of the specimen seems to be intact

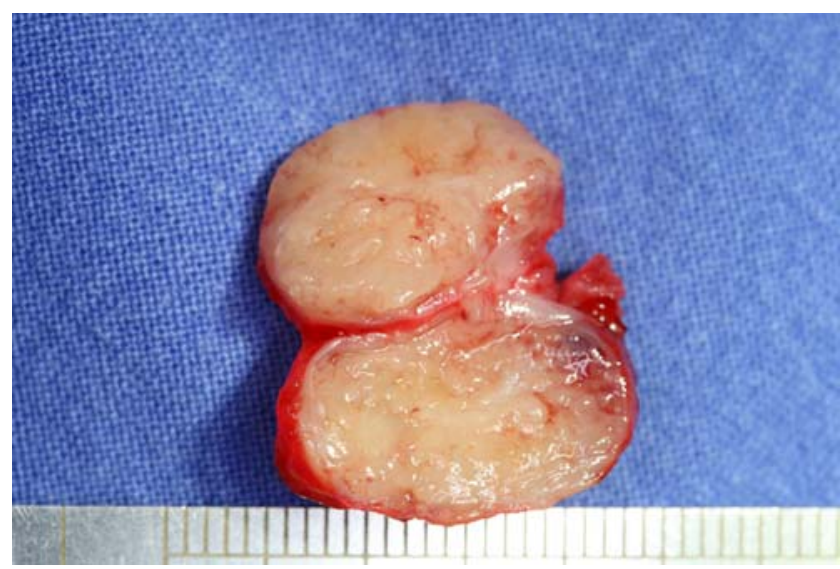

Fig. 2 When cut open, the specimen shows the presence of a solid tumor. A capsule seems to be present

With this rare and unexpected histopathological diagnosis, the therapeutic regimen had to be reconsidered. The patient was referred to a maxillo-facial surgery unit for a more radical resection at the site of the former tumor. Three weeks after initial removal of the tumor, the second resection was performed in general anesthesia at the site of the primary tumor. Neck dissection was not performed. The specimen, which was submitted for histopathological diagnosis was of a size of $14 \times 8 \times 8 \mathrm{~mm}$. The excised specimen, proofed to be free of tumor cells, and exhibited connective scar tissue in skeletal muscle tissue. Multinucleated giant cells, an inflammatory infiltration and sero-mucous salivary gland tissue, were also observed.

Nine months postoperatively, the patient is considered free of disease and is scheduled for follow-up controls every 3 months.

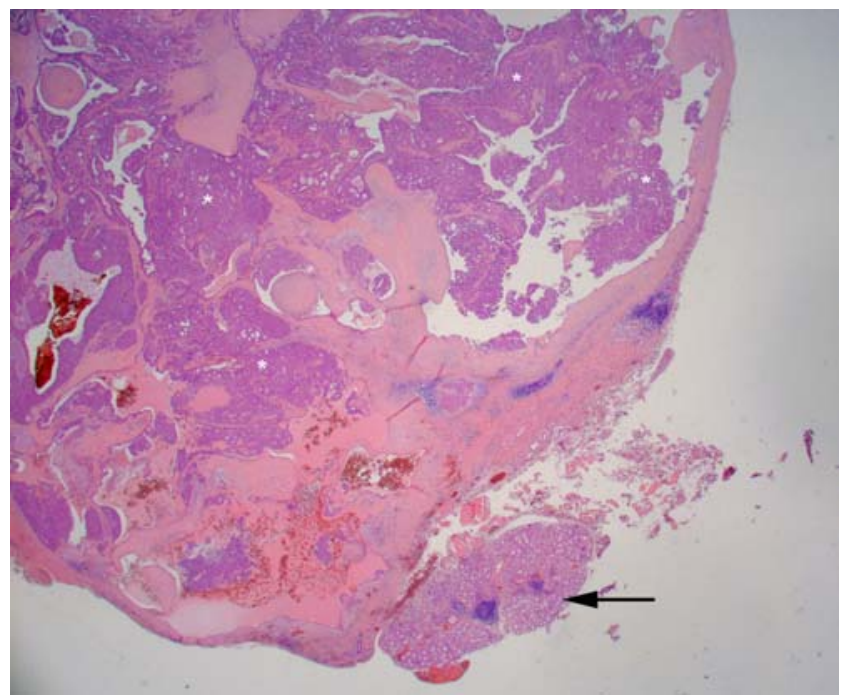

Fig. 3 Adjacent to neoplastic tissue $(*)$ sero-mucous salivary gland tissue (arrow) is seen (hematoxylin-eosin stain, original magnification $\times 25$ ) 


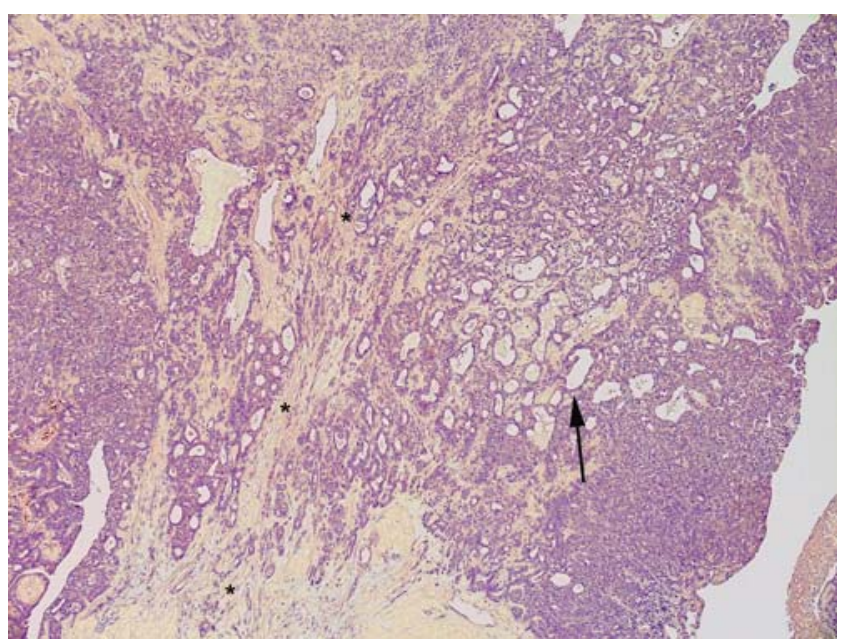

Fig. 4 Microphoto showing parts of the pre-existing pleomorphic adenoma characterized by a tubulo-glandular (arrow) component in a myxoid stroma $(*)$ (hematoxylin-eosin stain, original magnification $\times 50$ )

\section{Discussion}

Few series of intraoral minor salivary gland tumors have been published. One of the first extensive case series has been published by Chaudhry and coworkers [3]. This study included 94 own cases and 1,320 cases reported in the literature (1927-1960) with a total of 1,414 cases. From the 733 cases of pleomorphic adenoma, 38 occurred in the cheek compared to 476 cases of the palate indicating that pleomorphic adenomas of the cheek are quite rare. When considering malignant tumors alone $(n=520), 26$ cases of "malignant pleomorphic adenomas" (as this was the terminology in the 1960s) were registered (12 males, eight females, six non-specified/n.s.; age range 20-92 yrs,

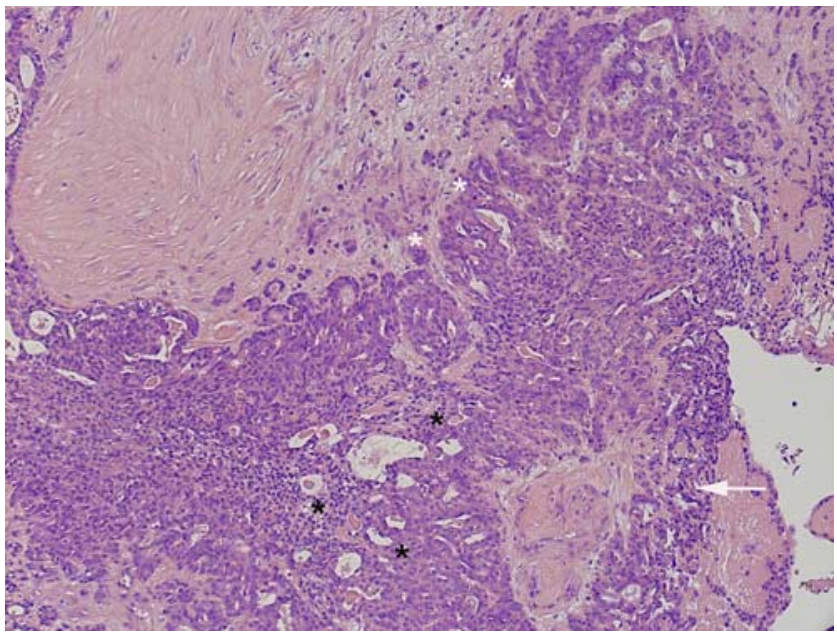

Fig. 5 Transitional area showing myoepithelial and epithelial cells in close association with adenoid tumor tissue revealing tubulo-cystic $($ black $*$ ), papillary (white $*$ ), and pseudopapillary (arrow) structures (hematoxylin-eosin stain, original magnification $\times 50$ )

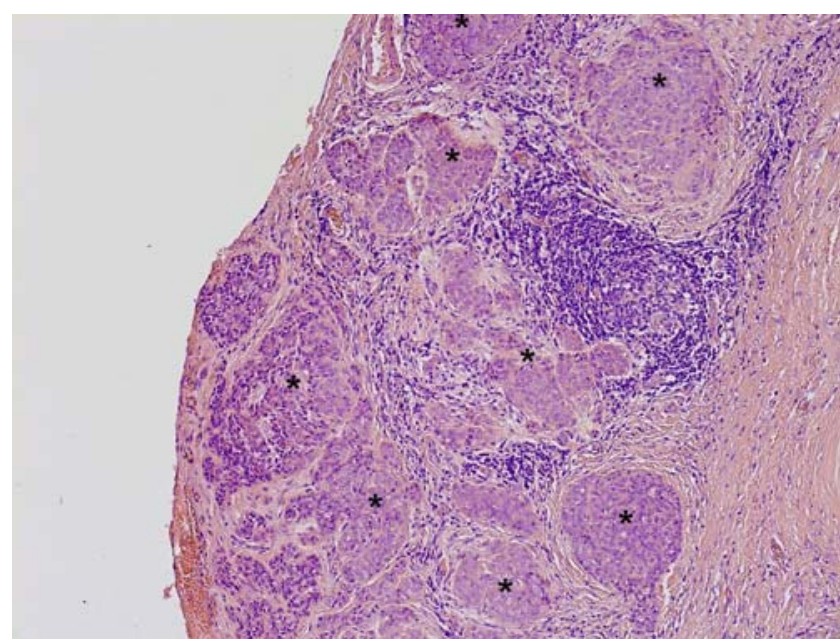

Fig. 6 Microphoto showing incompleteness of capsular integrity with infiltration of epithelial tumor islands (*; hematoxylin-eosin stain, original magnification $\times 50$ )

average age 48 yrs). Five cases of these were located in the cheek (13 palate, one lower lip, five jaws, and two n.s.). Out of the 94 cases from the authors own files, three cases of "malignant pleomorphic adenoma" of the palate were recorded and none were reported for the cheeks.

In 2005, Yih et al. reviewed 213 cases of minor salivary glands tumors of which 94 were malignant (44\%) [4]. Two cases of carcinoma ex pleomorphic adenoma were recorded $(0.9 \%)$. One case occurred in the buccal mucosa (male, $37 \mathrm{yrs}$ ); the other was located in the retromolar area (male, $75 \mathrm{yrs})$.

In a clinico-pathological study from Brazil, 546 cases of intraoral minor salivary gland tumors were reported [5]. Of these, only two cases of CEPA $(0.4 \%)$ were recorded. One case was located at the buccal mucosa; the other case was located at the alveolar ridge.

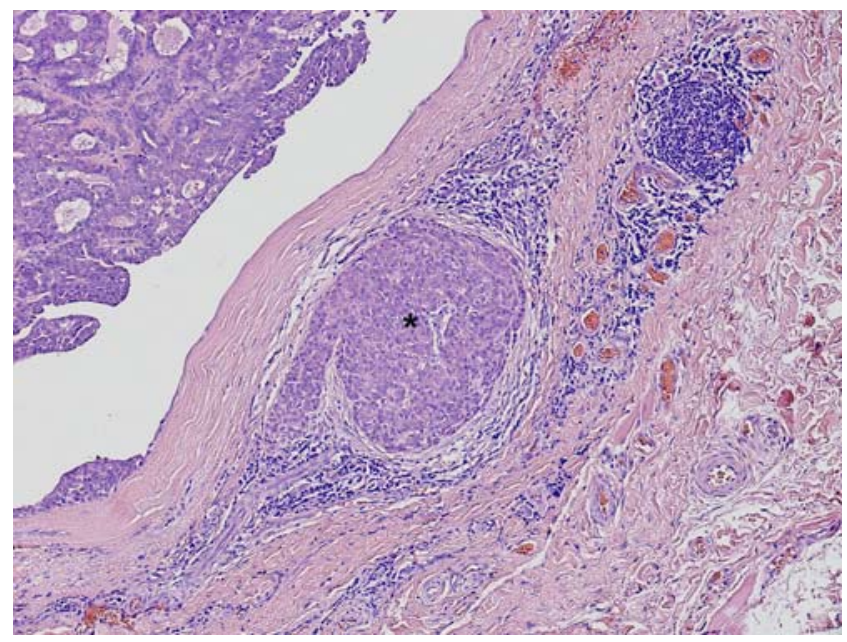

Fig. 7 Infiltration of capsular structures by an island of epithelial tumor cells $(*$; hematoxylin-eosin stain, original magnification $\times 100$ ) 
In another study of tumors of minor salivary glands $[n=75$, 46 cases of malignant tumors $(61.3 \%)]$ from Libya, two cases of CEPA were diagnosed [6]. Generally, there is agreement that the incidence of malignant tumors in minor salivary glands is high, ranging between $38.0 \%$ and $82 \%$ [10].

Recently, a large study from China has been published comprising 3,461 cases of salivary gland tumors which have been collected over a 50-year period [7]. One thousand three hundred ninety-two malignant tumors have been recorded of which 145 were classified as CEPAs: 81 were located in the parotid glands, 54 in the palate, four in the submandibular gland, and six in the floor of the mouth. No case of CEPA affecting the cheek was registered. From these data, it may be concluded that pleomorphic adenomas of minor salivary glands of the cheek are quite uncommon, and that CEPA in this anatomic region appears to be an extremely rare entity.

Reviews on CEPA are rare and usually focus on major salivary glands $[8,9]$. A direct comparison of CEPAs of major and minor salivary glands may be misleading. However, some understanding of this tumor entity might be derived from such reviews. In a clinico-pathologic review of 73 cases of CEPA in major salivary glands [9], 66 patients had primary and seven had recurrent tumors (47 males, 26 females; mean age $61 \mathrm{yrs}$ ). Metastasis occurred in $56 \%$ regionally and distantly in $44 \%$ of the cases. At 3 years, overall survival was $39 \%$, and at 5 years $30 \%$. The most frequent clinical complaint was a mass, present in 61 of 66 primary tumor patients $(92 \%)$. These data show that CEPA of the major salivary glands has to be considered an aggressive entity with high tendency for recurrence and fatal outcome. Generally, this statement may also be true for cases of CEPA of the buccal mucosa and other minor salivary glands.

Factors such as size of the neoplasia, persistence, and location of the tumor are of importance for the prognosis. In addition, the histopathologic sub-classification and grading of the tumor are also of prognostic relevance. Carcinomas ex pleomorphic adenomas are sub-classified into noninvasive, minimally invasive, and invasive. The first two groups have an excellent prognosis, while the latter has a more guarded prognosis [1].

In the present case, histopathological evaluation revealed definite but minimal invasion of the capsule with an invasive component of the malignant part of the tumor. In addition, the capsule was incomplete, particularly in the area of infiltration. As was expected, the surgical specimen after secondary surgery was free of malignant tumor tissue. Due to the histological findings in the primary tumor and the resection specimen of secondary surgery, this case was classified as minimal invasive and, therefore, the prognosis was expected to be good to very good. Postoperative controls, however, over a prolonged period of time, are mandatory.

This case shows that unexpected malignancy may occur in what primarily is considered to be a frank benign tumor of salivary gland tissue, and that only careful histopathological evaluation can help in the detection of such extremely rare salivary gland tumors including carcinoma ex pleomorphic adenoma. A recently published case report also raised the problem of a misleading histological diagnosis of a polymorphous low-grade adenocarcinoma in situ ex pleomorphic adenoma in a palatal minor salivary gland [10].

Acknowledgments The authors gratefully acknowledge the interdisciplinary work in the treatment of the patient by Prof. B. Hoffmeister, University Hospital, Charité, Berlin, Germany. The authors are also grateful to Dr. Th. Gaul, Berlin, Germany who kindly let us use the histological slides for evaluation and documentation of the case presented.

\section{References}

1. Gnepp DR, Brandwein-Gensler El-Naggar, Nagao T (2005) Carcinoma ex pleomorphic adenoma. In: Barnes L, Eveson JW, Reichart P, Sidransky D (eds) World Health Organization classification of tumours. Pathology and genetics of head and neck tumours. IARC Press, Lyon, pp 242-243

2. Brandwein M, Huvos AG, Dardick I, Thomas MJ, Theise MD (1996) Noninvasive and minimally invasive carcinoma ex mixed tumor: a clinicopathologic and ploidy study of 12 patients with major salivary tumors o low (or no?) malignant potential. Oral Surg Oral Med Oral Pathol Radiol Endod 81:655-664

3. Chaudhry AP, Vickers RA, Gorlin RJ (1961) Intraoral minor salivary gland tumors. An analysis of 1,414 cases. Oral Surg Oral Med Oral Pathol 14:1194-1226

4. Yih WY, Kratochvil FJ, Stewart JCB (2005) Intraoral minor salivary gland neoplasms: review of 213 cases. J Oral Maxillofac Surg 63:805-810

5. Pires FR, Pringle GA, de Almeida OP, Chen SY (2007) Intra-oral minor salivary gland tumors: a clinicopathological study of 546 cases. Oral Oncol 43:463-470

6. Jaber MA (2006) Intraoral minor salivary gland tumors: a review of 75 cases in a Lybian population. Int J Oral Maxillofac Surg 35:150-154

7. Li LJ, Li Y, Wen YM, Liu H, Zhao HW (2008) Clinical analyis of salivary gland tumor cases in West China in past 50 years. Oral Oncol 44:187-192

8. Lewis JE, Olsen KD, Sebo TJ (2001) Carcinoma ex pleomorphic adenoma: pathologic analysis of 73 cases. Hum Pathol 32:596-604

9. Olsen KD, Lewis JE (2001) Carcinoma ex pleomorphic adenoma: a clinicopathologic review. Head Neck 23:705-712

10. Kämmerer PW, Kreft A, Toyoshima T, Al-Nawas B, Klein MO (2009) Misleading initial histological diagnosis of a polymorphous low-grade adenocarcinoma in situ ex pleomorphic adenoma-a case report. Oral Maxillofac Surg 13:99-103 